\title{
ESTIMATION OF AEOLIAN DUNE MIGRATION OVER MARTIAN SURFACE EMPLOYING HIGH PRECISION PHOTOGRAMMETRIC MEASUREMENTS
}

\author{
Jungrack, $\operatorname{Kim}^{\mathrm{a}} *$ \\ ${ }^{a}$ Unviersity of Seoul, Department of Geoinformatics, Seoul, Korea (kjrr001@gmail.com)
}

Commission VI, WG VI/4

KEY WORDS: Martian dune, Surface migration, Photogrammetric control, High resolution image, Climate model

\begin{abstract}
:
At the present time, arguments continue regarding the migration speeds of Martian dune fields and their correlation with atmospheric circulation. However, precisely measuring the spatial translation of Martian dunes has been rarely successful due to the technical difficulties to quantitatively observe expected small surface migrations. Therefore, we developed a generic procedure to measure the migration of dune fields employing a high-accuracy photogrammetric processor and sub-pixel image correlator on the 25-cm resolution High Resolution Imaging Science Experiment (HiRISE). The established algorithms have been tested over a few Martian dune fields. Consequently, migrations over well-known crater dune fields appeared to be almost static for the considerable temporal periods and were weakly correlated with wind directions estimated by the Mars Climate Database. Only over some Martian dune fields, such as Kaiser crater, meaningful migration speeds ( $>1 \mathrm{~m} /$ year) considering photogrammetric error residual have been detected. Currently a technically improved processor to compensate error residual using time series observation is under development and expected to produce the long term migration speed over Martian dune fields where constant HiRISE image acquisitions are available.
\end{abstract}

\section{INTRODUCTION}

Martian dune migrations were reported by visual interpretations (Malin \& Edgett, 2001) or by the machine vision method (Bridges et al., 2012). However, a precise measurement of the spatial translation of Martian dunes has not usually been feasible due to technical difficulties induced by the relatively small migration of target objects and the large error in radiometric/geometric image controls. Considering the difficulties of achieving sufficient geodetic controllability and high precision measurement over the Martian surface where a ground survey is not available, the conventional pixel tracking method using in-orbital imagery and image correlation for terrestrial surface (Scambos et al., 1992; Kääb, 2002; Leprince et al., 2007) is not going to be reliable solution. Therefore, in this study, the development of a robust migration measurement tool and its validation over actual Martian dune fields has been conducted. The processor was designed to trace the estimated dune migration, albeit slight, over the Martian surface by 1) the introduction of very high-resolution ortho images and stereo analysis based on hierarchical geodetic control for better initial point settings; 2) positioning error removal throughout the sensor model refinement with a non-rigorous bundle-block adjustment, which makes possible the co-alignment of all images in a time series; and 3) improved subpixel coregistration algorithms with a refinement stage conducted on a pyramidal grid processor and a blunder classifier. The established algorithms were tested using high resolution HiRISE images over three dune fields.

\section{SCIENTIFIC AND TECHNICAL BACKGROUND}

Since the migration rates of Martian dune were expected to be small compared to the terrestrial correspondences, we first speculated the environmental characteristics of Martian dune fields and carefully chose the test areas. In addition, there were some intrinsic barriers to be tackled for the precise monitoring of Martian dune. In order to address such difficulties, a variety of machine vision and photogrammetric techniques were introduced and incorporated into the synthetic processing flows as described as follows.

\subsection{Moving dune over Martian surface}

Ever since aeolian features such as dune, yarding and wind steaks were first observed by early stage Marian missions (Thomas, 1982; Ward et al., 1985; Greeley et al., 1992), their origin has been actively investigated by the science community. Among them, dune fields which widely populated around polar region, crater floor and sometimes equatorial area once considered as the consequences of ancient climate condition that could produce active aeolian landforms. However, the clear landform changes over the Martian surface (Malin \& Edgett, 2001) had been recognized with the publications of higher spatial and temporal resolution Martian images especially over dune fields (Bridges et al., 2007). For instance, Bourke et al. (2008) summarized the observed Martian dune migration using Mars Global Surveyor's Mars Orbiter Camera imagery (resolution $<3 \mathrm{~m}$ ) and measured considerable change which is even comparable to terrestrial dunes. However, considering the insufficient resolutions of the base Mars Orbiter Laser Altimter (MOLA) Digital Terrain Model (DTM) and raw images for orthorectification and the potential geodetic error originated by the absence of proper control, nowadays, it was proposed the measurements were not genuine migrations. More recently, $25 \mathrm{~cm}$ resolution HiRISE images and precise control by COTS photogrammetric workstation (Kirk et al., 2008) provided a chance to observe potential dune migration precisely. Bridges et al. (2012) exploited such technical basis together with the COSI-CORR scheme (Leprince et al., 2007) and reported minor migration over Rabe crater. However, it is not certain whether the accuracies of the employed method which was developed for significant change of terrestrial landforms is applicable robustly for Martian dunes. In that context, it is necessary that the test areas for our dune migration scheme development possess a somewhat clear migration rate and direction that can be inferred by their morphologies and precedent observations. Based on such requirements and the availability of overlapping image coverage, theses target areas among those in Martian

\footnotetext{
* Corresponding author
} 
dune database (Hayward et al., 2007) and images were chosen over: 1) a clear barchan dune within Kaiser crater, including active bedform and gullies (Diniega et al., 2010), which are covered by the best HiRISE time series for the dune migration measurements; 2) Proctor crater, described as a partially active dune with a wind regime consisting of three opposing directions (Fenton et al., 2003); 3) the "wedge dune" over Wirtz crater which is usually considered to be formed by two prevailing wind regime (Parteli et al., 2009). Figure 1 shows the locations of the three test areas.

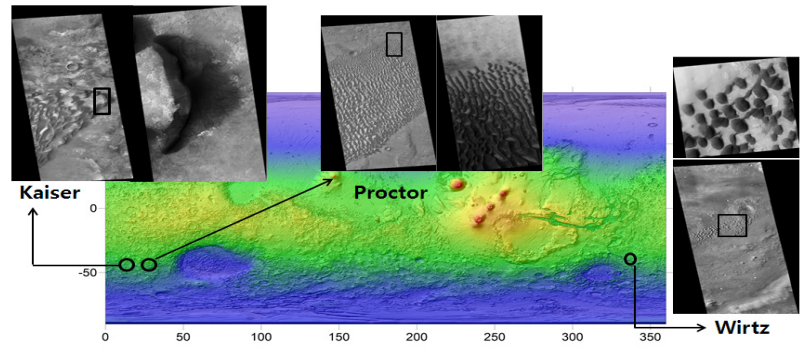

Figure 1. The locations of three target areas, Kaiser, Proctor and Witz for dune migration measurements and their Context Camera (CTX) and HIRISE images

\subsection{Technical backgrounds}

The main technical challenges for measuring Martian dune migration can be summarized as follows: 1) reliability of manual/automated measurements over textureless topography; 2) target image resolution and the feasibility of sub-pixel accuracy measurement; 3) temporal lags between the image acquisitions and the surface migrations; 4) radiometric changes of target surfaces. However the biggest technical issue for dune migration measurement is actually photogrammetric control of the image sequence. Although, the sensor orientation parameters of HiRISE images based on the NAIF SPICE kernel (https://naif.jpl.nasa.gov/naif/index.html) should be improved to attain precise co-registration, the available rigorous photogrammetric adjustment in public domain S/W packages, such as Integrated Software for Imagers and Spectrometers (ISIS), do not properly manipulate with the ideal sensor model of HiRISE mosaics. Therefore, we developed a conversion routine from the geometry of individual HiRISE images to the non-rigorous sensor representation and the space resection scheme by high-order polynomial adjustment. On the other hand, ground control points were taken from the established stereo DTM in order to achieve a co-aligned image sequence over the base topography. Figure 2 presents the evaluation of our geodetic control method. 22 control points with/without the setting over the active dune surface (Figure 2 (a)) were established and used for the non-rigorous sensor modelling. Generated ortho images for two corresponding HiRISE image pairs covering a period of one earth year were demonstrated anaglyphs (Figure 2 (b)). The observations using 11 check points and anaglyphs showed image disparity between two ortho image with the controls over active dune surface is largely reduced up to a maximum of 2 pixels along dune crest lines. Meanwhile the root-mean-square error of check points with the control of active dune surface were only increased up to 1.7 points in contrast to the case without the control points setting over the active dune surface ( 1.3 points). Therefore the validity of the non-rigorous sensor model as well as a small amount of dune migration rate was confirmed. After all, employing well distributed ground points in 3D space only excluding very highly active moving areas together with the pseudo controls by spice kernel information, it was expected to achieve stable geodetic accuracies for all our target areas.

Since conventional pixel-tracking methods using 2D image wrapping do not produce reliable measurements over the target images due to the absence of high-precision sub-pixel registration capability and the algorithm failures over dark and monotonous image textures, an in-house algorithm was established on the technical bases as follows:

1) A coarse-to-fine pyramidal measurement scheme employing the image wrapping with affine transformation

2) Scale-invariant feature transform (SIFT) was introduced to define the target points for tracing.

3) A machine vision algorithm using optical flow was introduced to make initial registrations.

4) Adaptive Least Squares correlator was employed to refine registration and to calculate registration cost.

5) Only reliable registration with sufficient matching cost value was delivered to the next pyramidal stage. Overall processing flows are shown in Figure 3.
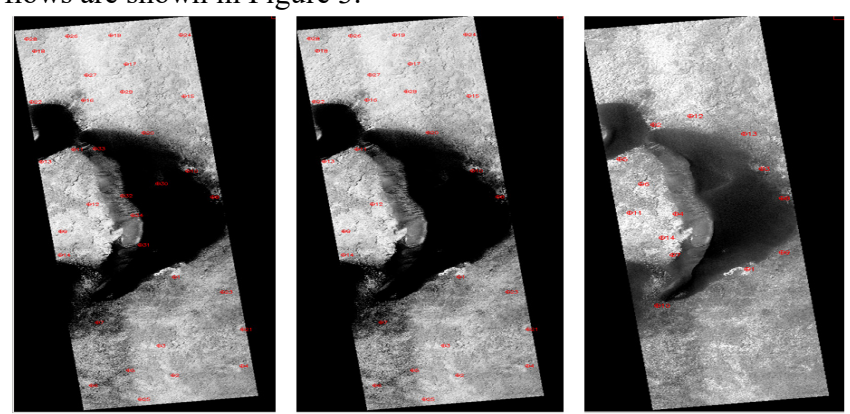

(a) Control point setting including dune surface (left), excluding dune surface and check points
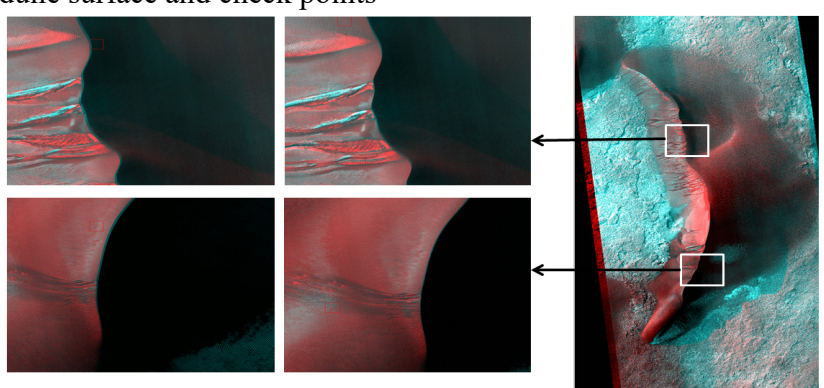

(b) Ortho image with dune surface (left) / without dune surface (right) controls

Figure 2. Validation of geodetic control using the strategy in this study

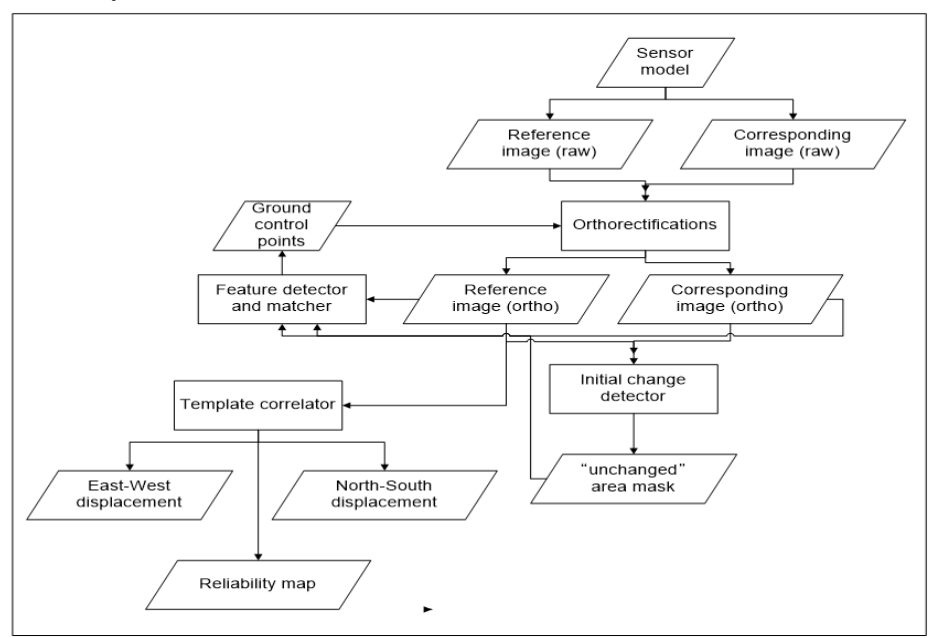

Figure 3. Overall processing flow for dune migration measurement 


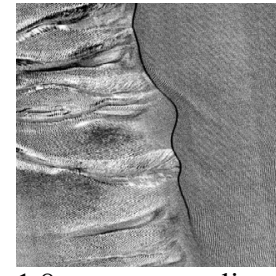

$1.8 \mathrm{~m}>$ crest line change/2 years

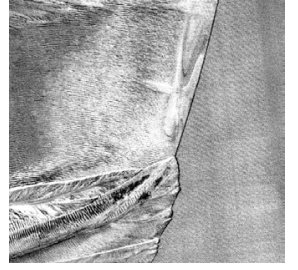

$1.2 \mathrm{~m}>$ crest line change/2 years

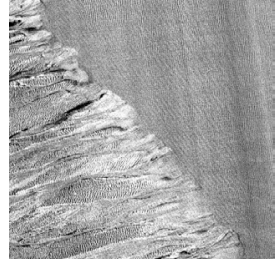

No obvious crest line change

Figure 4. Estimated dune crest line change using PCA analysis, Kaiser crater

\section{RESULTS}

To estimate the migration range at first, the crest line change was investigated using a time series image stack produced by our photogrammetric control strategy and Principle Component Analysis (PCA). The high order PCA component produced by 12 images over Kaiser crater covering a time period of two earth years demonstrated the maximum $1.8 \mathrm{~m}$ crest line change as shown in Figure 4. In spite of residual photogrammetric error, though it was minimized by our photogrammetric control strategy, it appeared that the estimated dune migration speed is within $1 \mathrm{~m} /$ year. Based on this observation, we applied our processing scheme over three target areas with the certain processing parameters optimised for that migration rate. The traced dune migration over Proctor was not very clear, but consistent migration trends were observed, as shown in Figure 5. According to the outcomes of those measurements, only the barchan dune in Kaiser crater showed the marginal migration speed following the morphological shape of the dune and maintained consistent migration trends (Figure 6). In the case of

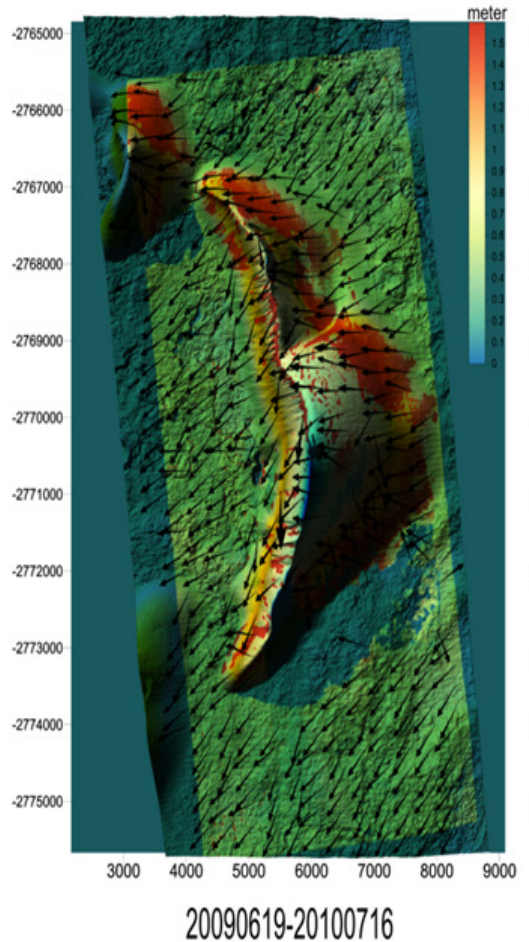

Sol 543-Sol 256

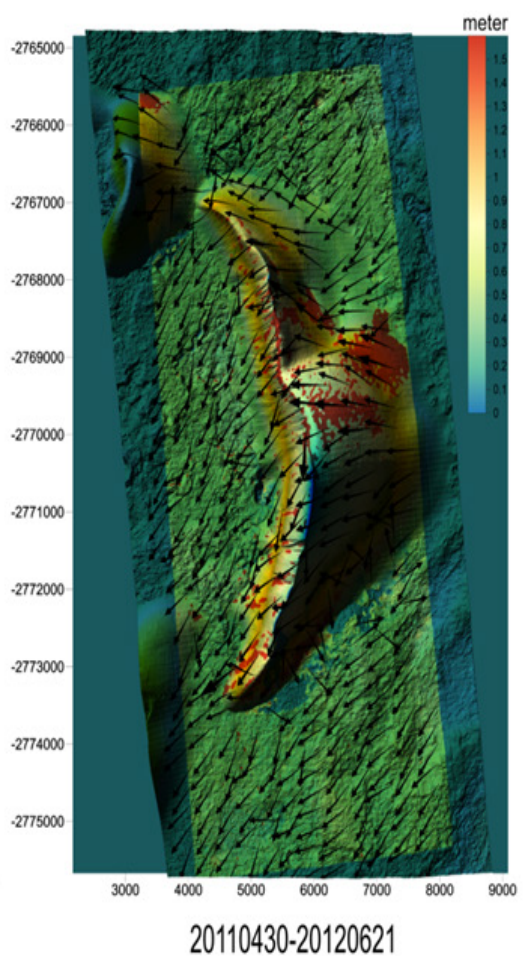

Sol 536-Sol 274

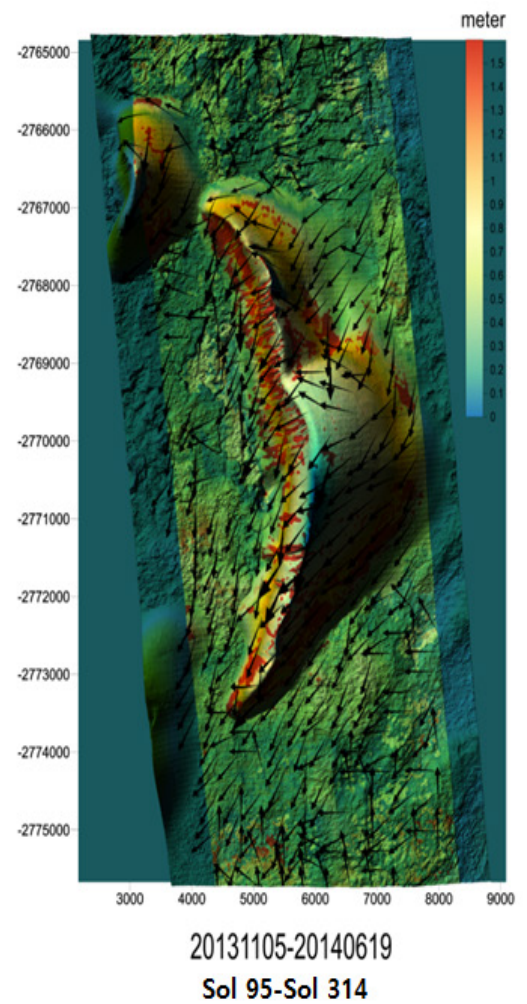

(a) Measurements of temporal change of migrations 

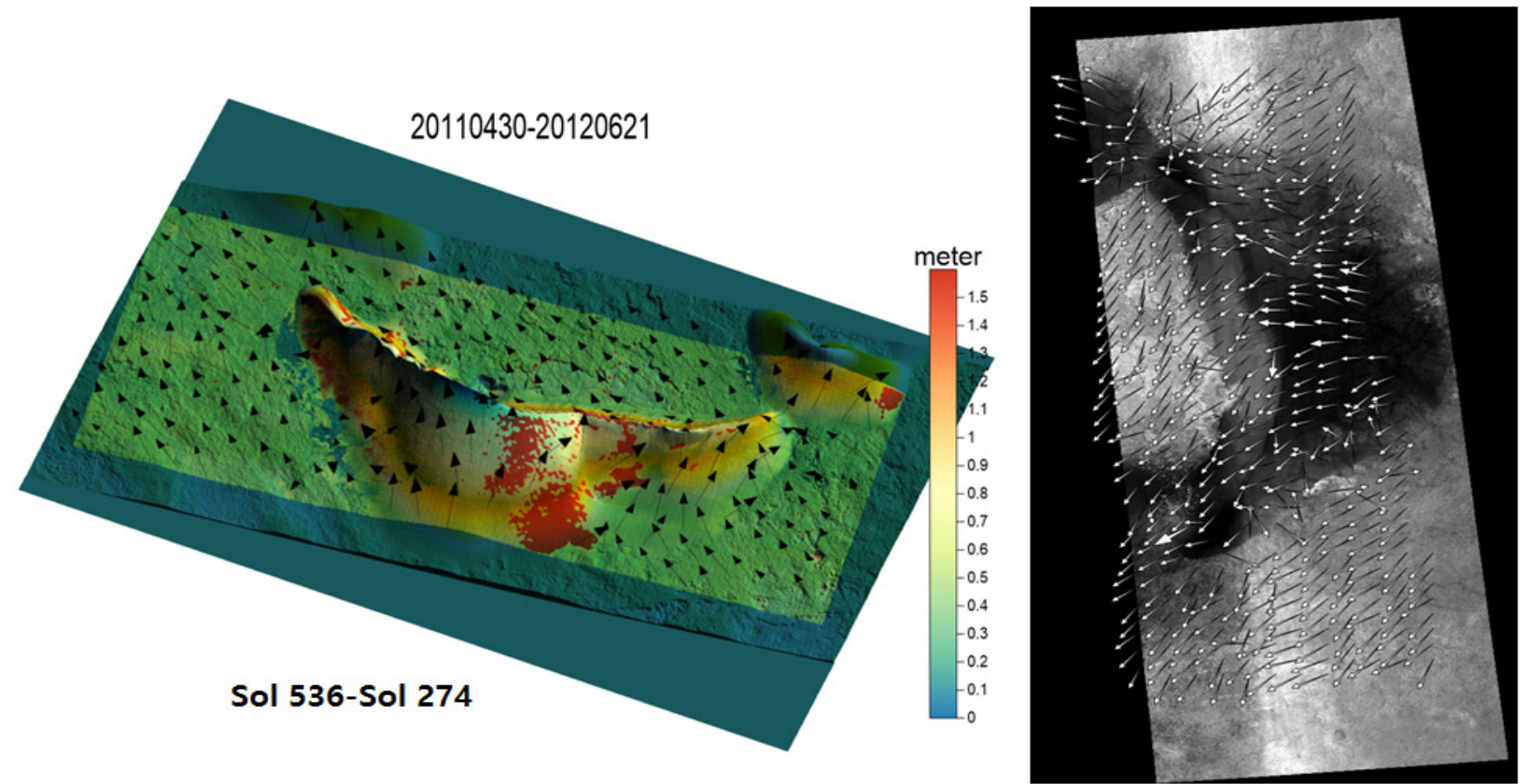

(b) An example of detailed migration measurements for 1 year period.

Figure 6. Traced dune migrations over Kaiser.

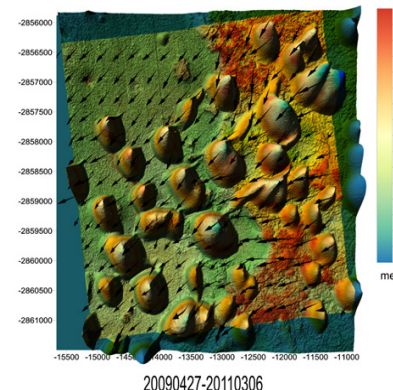

20090427-20110306

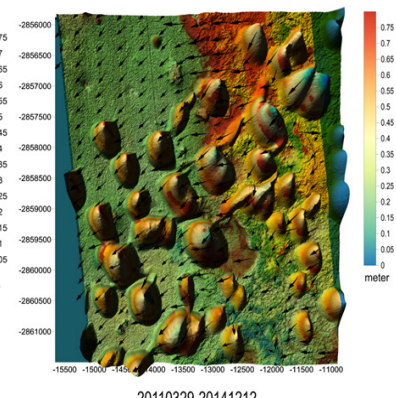

20110329-20141212

(a) Detected dune migration over the original HiRISE orthoimage

Figure 7. Traced dune migrations over Wirtz

\section{DISCUSSIONS}

So far, all our measurements have confirmed that Martian dune migrations by aeolian process are within a single meter per earth year. Our processing strategy gives a method to validate such limited migration visually. Since highly precise coregistration between two acquisition times is guaranteed, the ripple structure change which is strong evidence of dune migration (Silvestro et al., 2010) can be easily explored. Figure 8 shows the traced ripple structure migration during two earth year time period over Kaiser. In fact, any significant ripple pattern change was not observed. However, some false or unreliable measurements resulting from radiometric effects, such as seasonal frost (Figure 9 (a)), shadows, and undergoing CO2 gully (Figure 9(b) and see Reiss et al., 2010 for their formation theory), were detected, though the blunder detection of the established algorithms removed most of the erroneous measurements. The other outcome confirmed by the measurement is the weak correlation with Martian general circulation and dune migrations. As shown in Table.1 which was extracted by the Mars General Circulation Model 1.4, (Millour et al., 2008), the wind vectors over dune fields are continuously changing according to seasonal atmospheric circulation. However, all our
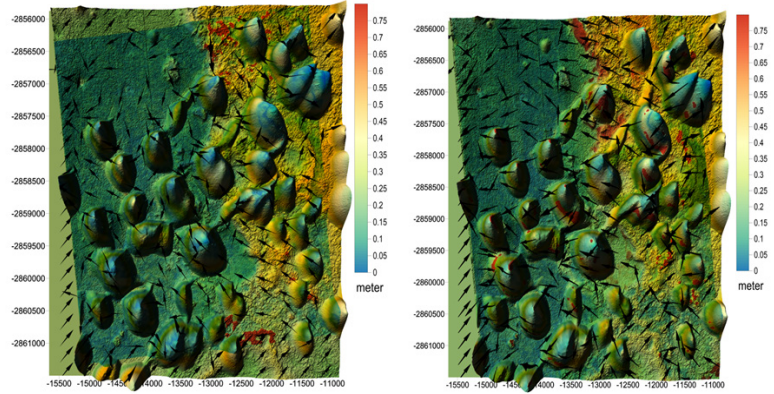

(b) After applying offset ( $>0.3$ pixel) value estimated from jittered portions.

measurements showed quite consistent migration rates and directions. Therefore, it was proven that the dune migrations in our measurement are governed by local wind regime rather than general atmospheric circulation.
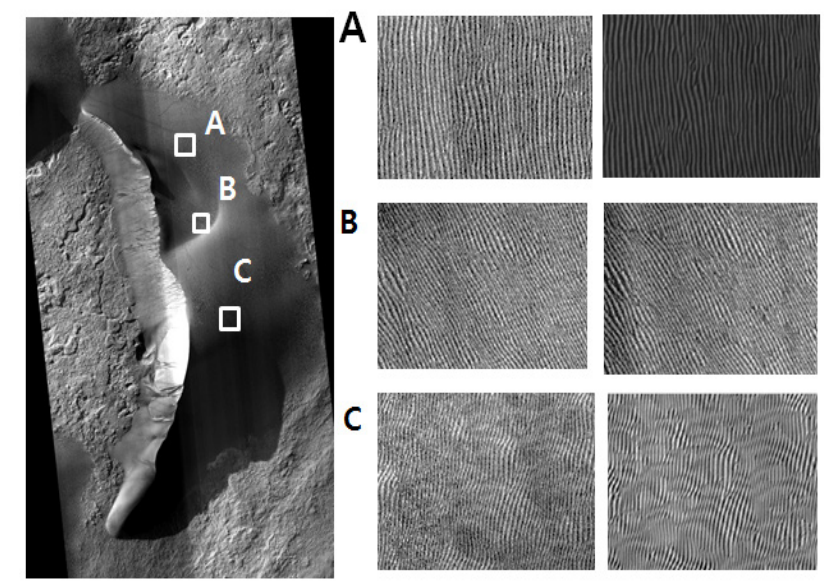

Figure 8. Ripple structures migration after photogrammetric adjustments 


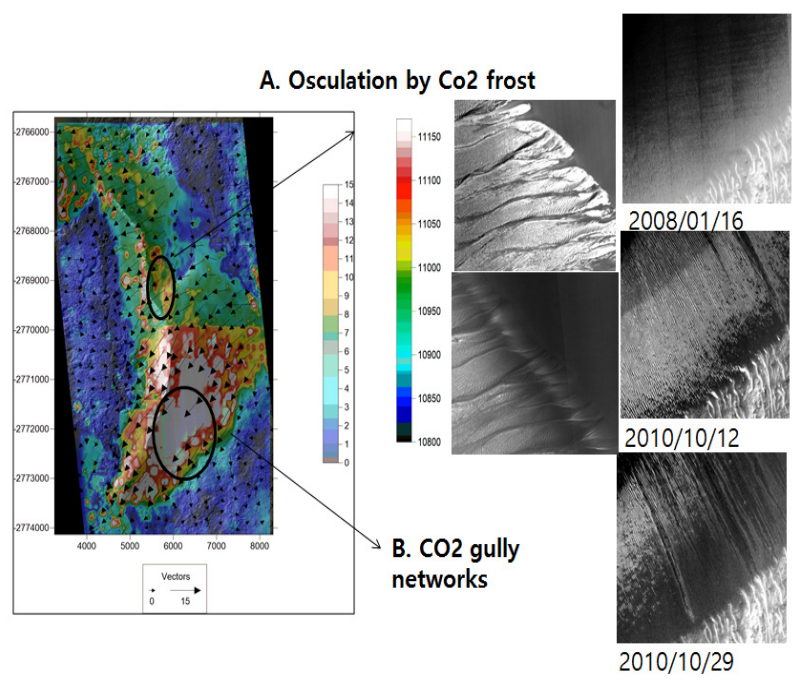

Figure 9. Examples of artifacts by radiometric changes over surfaces ESP 027667 (2012/06/21) - ESP037372 (2014/07/17) a. Osculation by $\mathrm{Co} 2$ frost, b. artefacts by shadow and active seasonal $\mathrm{CO} 2$ gully networks which rejected by blunder detection component

\begin{tabular}{|l|l|l|l|}
\hline Observations & $\begin{array}{l}\text { Horizontal } \\
\text { wind speed } \\
(\mathrm{m} / \mathrm{s})\end{array}$ & $\begin{array}{l}\text { W-E } \\
\text { wind } \\
(\mathrm{m} / \mathrm{s})\end{array}$ & $\begin{array}{l}\text { S-N } \\
\text { wind } \\
(\mathrm{m} / \mathrm{s})\end{array}$ \\
\hline Kaiser 2009/06/19 - & 2.546 & -0.178 & -2.540 \\
\cline { 2 - 4 } $2010 / 07 / 16($ Sol 543-256) & 8.785 & 8.740 & 0.890 \\
\hline \multirow{2}{*}{$\begin{array}{l}\text { Kaiser 2011/04/30- } \\
2012 / 06 / 21(\text { Sol536-274) }\end{array}$} & 3.764 & -3.285 & -1.836 \\
\cline { 2 - 4 } $\begin{array}{l}\text { Kaiser 2013/11/0- } \\
\text { 2014/06/19 (Sol95-314) }\end{array}$ & 3.791 & 1.938 & 3.258 \\
\cline { 2 - 4 } & 5.531 & 3.753 & -1.081 \\
\hline
\end{tabular}

Table 1. Wind vector extracted by Martian General Circulation Model over Kaiser.

\section{CONCLUSION AND FUTURE WORK}

We developed a procedure to measure the Martian migration over geodetically controlled images and applied it over a few target areas. Only the dune over Kaiser crater showed meaningful migration speeds $(<1 \mathrm{~m} /$ year), although it still includes the residual photogrammetric error. It appeared that the observed dune migrations by some precedent studies are not genuine but are mostly the results of photogrammetric errors, if a proper geodetic control was not applied. Illumination changes combining topographic reliefs and seasonal surface conditions might induce many "false dune migration" measurements.

After all, the well-known crater dune fields appeared to be quite static for considerable temporal periods, although parts of their migrations were correlated with the dune morphology and possibly with the wind directions estimated by the Mars Climate Database (Millour et al. 2015). Currently, a technically improved processor to compensate for residual error using time series observation is under development and expected to produce long-term migration speeds over the Martian dune fields where constant HiRISE image acquisitions are available. In order to achieve this purpose, advanced time series analysis techniques to segregate photogrammetric errors and aeolian migration are under development and algorithms will be updated to find denser measurements.

Moreover, the volumetric changes of Martian dunes will be further traced by means of stereo analysis and photoclinometry.

\section{ACKNOWLEDGEMENTS}

The research leading to these results has received funding from the European Union's Seventh Framework Programme (FP7/2007-2013) under iMars grant agreement Nr. 607379.

\section{REFERENCES}

Bourke, M. C., Edgett, K. S., \& Cantor, B. A. 2008. Recent aeolian dune change on Mars. Geomorphology, 94(1), pp.247255 .

Bridges, N. T., Ayoub, F., Avouac, J. P., Leprince, S., Lucas, A., \& Mattson, S. 2012. Earth-like sand fluxes on Mars. Nature, 485(7398), pp.339-342.

Bridges, N. T., Geissler, P. E., McEwen, A. S., Thomson, B. J., Chuang, F. C., Herkenhoff, K. E., ... \& Martínez-Alonso, S. 2007. Windy Mars: A dynamic planet as seen by the HiRISE camera. Geophysical Research Letters, 34(23).

Diniega, S., Byrne, S., Bridges, N. T., Dundas, C. M., \& McEwen, A. S. 2010. Seasonality of present-day Martian dunegully activity. Geology, 38(11), 1047-1050.

Fenton, L. K., Bandfield, J. L., \& Ward, A. 2003. Aeolian processes in Proctor Crater on Mars: Sedimentary history as analyzed from multiple data sets. Journal of Geophysical Research: Planets (1991-2012), 108(E12)

Greeley, R., N. Lancaster, S. Lee, and P. Thomas, Martian aeolian processes, sediments, and features, in Mars, edited by H. H. Kieffer et al., pp. 730-766, Univ. of Ariz. Press, Tucson, 1992.

Hayward, R. K., Mullins, K. F., Fenton, L. K., Hare, T. M., Titus, T. N., Bourke, M. C., ... \& Christensen, P. R. 2007. Mars global digital dune database and initial science results. Journal of Geophysical Research: Planets, 112(E11)..

Kääb, A. 2002. Monitoring high-mountain terrain deformation from repeated air-and spaceborne optical data: examples using digital aerial imagery and ASTER data. ISPRS Journal of Photogrammetry and remote sensing, 57(1), 39-52.

Kirk, R. L., Howington-Kraus, E., Rosiek, M. R., Anderson, J. A., Archinal, B. A., Becker, K. J., ... \& Holmberg, I. M. 2008. Ultrahigh resolution topographic mapping of Mars with MRO HiRISE stereo images: Meter-scale slopes of candidate Phoenix landing sites. Journal of Geophysical Research: Planets, 113(E3).

Leprince, S., Ayoub, F., Klinger, Y., \& Avouac, J. P. 2007. Coregistration of optically sensed images and correlation (COSICorr): An operational methodology for ground deformation measurements. In Geoscience and Remote Sensing Symposium, 2007. IGARSS 2007. IEEE International (pp. 1943-1946). IEEE.

Malin, M. C., \& Edgett, K. S. 2001. Mars global surveyor Mars orbiter camera: interplanetary cruise through primary mission. Journal of Geophysical Research: Planets, 106(E10), 23429-23570. 
Millour, E., Forget, F., González-Galindo, F., Spiga, A., Lebonnois, S., Montabone, L., ... \& Lefevre, F. 2008. The latest (version 4.3) Mars climate database. Mars Atmosphere: Modeling and Observations, 1-4.

Parteli, E. J., Almeida, M. P., Durán, O., Andrade, J. S., \& Herrmann, H. J. 2009. Sand transport on Mars. Computer Physics Communications, 180(4), 609-611.

Reiss, D., Erkeling, G., Bauch, K. E., \& Hiesinger, H. 2010. Evidence for present day gully activity on the Russell crater dune field, Mars. Geophysical Research Letters, 37(6).

Scambos, T. A., Dutkiewicz, M. J., Wilson, J. C., \& Bindschadler, R. A. 1992. Application of image crosscorrelation to the measurement of glacier velocity using satellite image data. Remote sensing of environment, 42(3), 177-186.

Silvestro, S., Fenton, L. K., Vaz, D. A., Bridges, N. T., \& Ori, G. G. (2010). Ripple migration and dune activity on Mars: Evidence for dynamic wind processes. Geophysical Research Letters, 37(20).

Thomas, P. 1982. Present wind activity on Mars: Relation to large latitudinally zoned sediment deposits. Journal of Geophysical Research: Solid Earth, 87(B12), 9999-10008.

Ward, A. W., Doyle, K. B., Helm, P. J., Weisman, M. K., \& Witbeck, N. E. 1985. Global map of eolian features on Mars. Journal of Geophysical Research: Solid Earth, 90(B2), 2038-2056. 